\title{
Vida, palabra y técnica en la enseñanza de la filosofía
}

Life, word and technique in the teaching of philosophy

\author{
Abel Miró i Comas ${ }^{1}$ \\ Universitat de Barcelona
}

Recibido: 29.09.2021

Aceptado: 25.11.2021

\section{Resumen}

La clase de filosofía, desde la perspectiva del docente, no debe considerarse como una mera actividad transeúnte o predicamental. El presente estudio quiere examinarla, siguiendo la metafísica de la vida de Tomás de Aquino, como una obra vital, que requiere, por un lado, que el profesor se haga una sola cosa — una sola vida, podemos decir - con la doctrina que va a explicar y, por el otro, que esta intelección actual, sin movimiento alguno, dé lugar a la «concepción»y al «parto» de lo entendido en una palabra del corazón, la cual, por su dinamismo intrínseco, tiende, a su vez, a manifestarse exteriormente en una palabra sonora, en un «verbum vocis». Esta exteriorización, por la cual aquella íntima operación que constituye la vida del que filosofa se corporeiza en forma de «diálogo», es, precisamente, la clase de filosofía. La técnica pedagógica debe tener en cuenta el orden intrínseco por el cual la vida humana, mediante la formación de una palabra del corazón, procede a su propia perfección, y no debe olvidar que el perfeccionamiento vital del profesor es causa (instrumental) del perfeccionamiento vital del alumno; es decir, quien no «produce», quien no «engendra», quien no «crea» interiormente lo que está explicando —independientemente de si se trata o no de una novedad - difícilmente ofrecerá unos medios adecuados para que el alumno conciba y dé a luz, en la intimidad de su mente, a un «verbum cordis».

\footnotetext{
${ }^{1}$ abel.miro@ub.edu https://orcid.org/0000-0003-2239-308X 
Palabras clave: Tomás de Aquino, maestro, «verbum cordis», metafísica, vida.

\begin{abstract}
The philosophy class, from the teacher's perspective, should not be considered as a mere transient or predicamental activity. The present study aims to examine it, following Thomas Aquinas' metaphysics of life, as a vital work, which requires, on the one hand, that the teacher becomes one thing - one life, we can say - with the doctrine he is going to explain and, on the other hand, that this actual intellection, without any movement, gives rise to the «conception» and «birth» of what is understood in a «verbum cordis», which, by its intrinsic dynamism, tends, in its turn, to manifest itself externally in a sonorous word, in a «verbum vocis». This externalisation, by which that intimate operation which constitutes the life of the philosopher is embodied in the form of a «dialogue», is precisely the philosophy class. The pedagogical technique must take into account the intrinsic order by which human life, through the formation of a word of the heart, proceeds to its own perfection, and must not forget that the vital perfection of the teacher is the (instrumental) cause of the vital perfection of the pupil; that is to say, who does not «produce», who does not «engender», who does not «create» inwardly what he is explaining - regardless of whether or not it is a novelty - will hardly offer adequate means for the pupil to conceive and give birth, in the intimacy of his mind, to a «verbum cordis».
\end{abstract}

Keywords: Thomas Aquinas, teacher, «verbum cordis», metaphysics, life.

\title{
1. La filosofía como «vida» del que filosofa
}

La primera tesis que me gustaría exponer es que la filosofía, tomada en su sentido propio, no debe considerarse como una profesión, como un pasatiempo o como un mero hobby, sino como la «vida» del que filosofa. No se puede entender un ente al margen de su «obra», que nos proporciona la «medida» en vistas a la cual este ente debe ser concebido. Un cerezo, por ejemplo, está ordenado a la producción de cerezas como a su operación propia, que es su bien, 
su fin, su perfección; no podremos valorar debidamente a un cerezo concreto si no tenemos en cuenta su mayor o menor aptitud para colmar la capacidad de perfección adjetiva, accidental, secundaria, que está virtualmente contenida en su naturaleza.

En el caso del hombre, al tratarse de un ente libre, y no únicamente de un ente natural, la situación es más compleja; el hombre, a diferencia de las plantas y de los animales irracionales, no sólo puede moverse hacia un fin determinado, sino que puede imponerse a sí mismo el fin hacia el cual se mueve. ${ }^{2}$ Esta capacidad de autodeterminación, sin embargo, no es ilimitada, pues el ser humano está naturalmente ordenado hacia su fin o bien último - la felicidad-, que «no puede no querer [non potest non velle]» ${ }^{3}$. Lo que sí puede elegir la voluntad -y que constituye, de hecho, su primera elección- es la concreción o particularización del fin supremo y, consiguientemente, de los medios que conducen a él; aquello que Eudaldo Forment llama «el fin último concreto» ${ }^{4}$.

Esta delimitación del irrenunciable apetito al bien en general es la obra sin la cual no puede entenderse a un hombre singular, la obra que da la medida de su «vida», que ha ido moldeando a la luz de un ideal; aquella obra a la que está llamado como a su quehacer personal en el mundo, en la cual pone su gozo y por la cual busca la convivencia con los amigos: ${ }^{5}$ «la vida de cada hombre parece que consiste en aquello que máximamente le deleita [vita uniuscuiusque hominis videtur esse id un quo maxime delectatur], y que persigue por encima de todo [et cui maxime intendit]; aquello por lo cual quiere principalmente convivir con los amigos [in hoc praecipue vult quilibet convivere amico], como se dice en el libro IX de la Ethica» ${ }^{6}$.

\footnotetext{
${ }^{2}$ «Por encima de estos animales [los irracionales], se encuentran aquellos que también se mueven a sí mismos respecto el fin [movent seipsa, etiam habito respectu ad finem], que se imponen ellos mismos [quem sibi praestituunt] [SANTO TomÁs, Summa Theologiae, I, q.18, a.3, in c]».

${ }^{3}$ Ídem.

${ }^{4}$ Forment, Eudaldo, Catecismo de la Suma contra los Gentiles, Alicante, Cobel, 2015.

${ }^{5} \mathrm{Cf}$., Bofill, Jaume, «D'una teoria de l'acte a una teoria de la relació interpersonal. Notes d'ontologia», en: Convivium, núm. 17-18, 1964, pp. 24-48.

${ }^{6}$ SAnto Tomás, Summa Theologiae, II-II, q.179, a.1, in c.
} 
El profesor de filosofía honesto — es decir, el profesor para quien el filosofar es su vidabusca la convivencia con sus alumnos para compartir con ellos aquella operación que máximamente le deleita, y que persigue por encima de todo, a saber, la investigación y —en la medida de lo posible - la contemplación de la verdad. Es importante subrayar la palabra operación, porque no se trata de asumir pasivamente aquello que, en el pretérito, fue pensado por un gran maestro $;^{7}$ la actividad filosófica no consiste en contemplar las huellas impresas por un gigante sobre la arena, sino en utilizar esas huellas, que son los textos que la tradición nos ha legado, y que deben leerse con extrema detención, para pensar por nosotros mismos aquello pensado por los grandes filósofos.

El profesor de filosofía genuino, cuando explica el Poema de Parménides en clase, no se limita a exponer lo pensado por Parménides como si fuera un hecho histórico, un «cadáver de pensamiento», una «huella» del camino que antaño recorrió el filósofo de Velia; este procedimiento, si bien es compatible con la erudición, no lo es con el filosofar; así como el filosofar no es compatible con los «cadáveres de pensamiento», pero sí con la erudición. El profesor de filosofía genuino, decíamos, cuando expone el Poema de Parménides en clase, no sólo piensa - o al menos se esfuerza por pensar - lo pensado por Parménides en su Poema, sino que, estrictamente hablando, es el Poema de Parménides, deviene una sola vida con él.

Al decir esto, no estamos abandonando la precisión filosófica para adoptar el lenguaje metafórico de la poesía, sino que permanecemos absolutamente fieles a la terminología de la escolástica aristotélico-tomista, que no por ser exacta, deja de ser sugerente: «Lo inteligible

\footnotetext{
${ }^{7}$ Escuchar, como remarca Santo Tomás comentando el segundo versículo del Psalmo XLIII (XLIV en la edición de la Nova Vulgata) — «Con nuestros oídos lo hemos escuchado, nos lo han anunciado nuestros padres»—, no sólo implica un aspecto receptivo, sino también uno de activo: «Lo hemos escuchado. La escucha es necesaria para la alcanzar sabiduría: "Si amas el escuchar, serás sabio [Sir 6, 34]"; también es necesaria para quien ya es sabio: "El sabio, escuchando, será más sabio [Pr 1,5]". Escuchar, en definitiva, es conveniente para cualquier hombre, pues nadie es capaz de conocer por sí solo todas las cosas que pertenecen a la sabiduría, y esto se explica porque nadie es sabio a menos que sea instruido por otro [...]. Con nuestros oídos. Escucha con sus oídos aquel que escucha sujetando sus oídos a la razón. Esto se explica porque se dice de alguien que es un hombre en la medida que tiene razón. Cuando las orejas están sujetas a la razón, son humanas; cuando no están sujetas a la razón, son bestiales: "Quien tenga oídos para escuchar, que escuche [Lc 8, 8]" [...]. Nuestros padres nos o han anunciado. Aquí se revela que han escuchado a aquellos que [...] han podido enseñar la verdad porque son antiguos [SANTO TOMÁs, Super Psalmo 43 n.1]». La cursiva es nuestra.
}

Volumen 2. Número 1. Enero - Junio 2022

ISSN: 2745-0333 (En línea) 
en acto es el entendimiento en acto [intelligibile in actu est intellectus in actu], así como lo sensible en acto es el sentido en acto [sensible in actu est sensus in actu]. Pero lo inteligible se distingue del entendimiento en la medida que los dos están en potencia, como se ve claramente en el sentido, pues ni la vista ve actualmente, ni aquello visible es visto actualmente, si la vista no es informada por la especie de lo visible, ${ }^{8}$ de modo que la vista y lo visible se hagan uno» ${ }^{9}$.

Lo entendido y el entendimiento devienen algo uno en cuanto que lo entendido se encuentra en el entendimiento a través de una semejanza representativa o «species intelligibilis» ${ }^{10}$; cuando se produce está unión, o, más exactamente, esta unidad, ${ }^{11}$ el entendimiento entiende en acto y lo entendido es entendido en acto: «entendemos y sentimos algo porque el entendimiento y el sentido en acto están informados por la especie sensible o inteligible. Y sólo por eso se distinguen el sentido y el entendimiento de lo sensible y lo inteligible, porque ambos están en potencia» $^{12}$.

En otro texto, Santo Tomás se expresa más radicalmente, no sólo habla de una unidad entre el inteligible en acto y el entendimiento en acto, sino de una unidad, además, entre el inteligible en acto y el inteligente en acto: «el inteligente y lo entendido [intelligens et intellectum], en cuanto que de ellos procede un único efecto [effectum unum quid] que es el intelecto en acto [intellectus in actu], son un solo principio de este acto que es el entender [intelligere]; y afirmo que de ellos [ex eis] [del inteligente y de lo entendido] se hace una sola cosa, en cuanto que el

\footnotetext{
${ }^{8} \mathrm{La}$ «species» de la cosa es una semejanza representativa de ella; puede ser sensible o inteligible dependiendo de si informa o especifica a una facultad perteneciente a la parte sensitiva del alma o bien a la parte intelectiva. El término latino «especie», en su sentido cotidiano, no técnico, sugiere la faz y el rostro de algo como «aquello que revela lo que es». Así, en lengua catalana, cuando hablamos de algo coherente, decimos que «té cara i ulls» — que «tiene cara y ojos»—, en tanto que muestra, en su rostro y en su mirada, el sentido, el término, la intención a la que se ordenan sus actos segundos o accidentales [Cf., CANALS, Francisco, «Ser y operación», en ÍDEM, Tomás de Aquino. Un pensamiento siempre actual y renovador, Barcelona, Scire, 2004, p. 160].

${ }^{9}$ SAnTo TOMÀs, Summa contra Gentiles, cap. 51, n. 6.

${ }^{10} \mathrm{El}$ adjetivo «inteligible» hace referencia a la esencia de algo en cuanto presente en el entendimiento de alguien, o, dicho en otras palabras, hace referencia a una realidad intencional, representativa, por medio de la cual el hombre cognoscente se hace una sola cosa con lo conocido.

${ }^{11}$ Decimos «unidad», pues no se trata de una yuxtaposición de dos entes con sus actos respectivos, sino de un solo acto.

${ }^{12}$ SAnTo TomÀs, Summa Theologiae, I, q.14, a.2.
}

Volumen 2. Número 1. Enero - Junio 2022

ISSN: 2745-0333 (En línea) 
intelecto se une al inteligente [...] por medio de una semejanza [secundum quod intellectum coniungitur intelligenti sive $[\ldots]$ per similitudinem $]\rangle^{13}$.

Es todo el hombre, y no sólo una de sus partes - la intelectiva, en este caso- quien entiende el Poema de Parménides y deviene una sola vida con él al entenderlo; así pues, cuando un hombre pasa de la simple posibilidad de conocer el Poema hasta la actualización de esta posibilidad - en un grado mayor o menor, dependiendo de la intensidad con que haya penetrado en su contenido-, se compromete todo entero, porque la operación, en rigor, sólo puede atribuirse a lo que propiamente existe, que no es el accidente cualitativo de la facultad, sino su sujeto de inherencia, a saber, la substancia individual, la hipóstasis, la persona. ${ }^{14}$

Conviene enfatizar, además, que el sujeto que conoce y que se hace una sola vida con lo conocido - el Poema de Parménides, en nuestro ejemplo - no es el hombre, sino este hombre particular. Todo hombre es indudablemente miembro de una especie determinada, pero esta pertenencia no lo comprende, no lo explica, en todas sus dimensiones; en cualquier hombre se encuentra la esencia humana, pero no hay ningún individuo humano en el cual sólo se encuentren la animalidad y la racionalidad, pues siempre se estarán dando en él ciertos elementos absolutamente refractarios a entrar en composición con los que son típicos de su especie, ya que, respecto de estos últimos, aquéllos constituyen algo así como simples modalidades suyas, radicadas todas por igual en el principio individualizador de la forma substancial del hombre - el alma - que es la «materia signata sub determinatis dimensionibus existens» ${ }^{15}$. De aquí deduciremos una consecuencia importantísima: cada individuo racional es verdaderamente excepcional, pues encarna de una manera única e irreiterable la condición específica de animal racional. ${ }^{16}$ Evidentemente, estamos inscritos en

\footnotetext{
${ }^{13}$ SAnto Tomàs, De Veritate, q.8, a.6, in c.

${ }^{14}$ SANTO TOMÀs, Summa Theologiae, I, q.29, a.2, ad 1.

${ }^{15}$ SANTO TOMÀs, De Veritate, q.10, a.5, in c.

${ }^{16}$ «La esencias de las cosas [quidditates rerum] no son diferentes de las cosas, a menos que sea por accidente [per accidens]; por ejemplo, no es lo mismo la esencia del hombre blanco que el hombre blanco, porque la esencia del hombre no contiene en sí misma nada más que lo que pertenece a la especie de hombre; pero "hombre blanco" contiene algo que está más allá de lo que se encuentra en la especie humana [SANTO TOMÀs, Sentencia De anima, III, lect. 8, n.7]».
}

Volumen 2. Número 1. Enero - Junio 2022 ISSN: 2745-0333 (En línea) 
el seno de la especie humana, pero como versiones individuales de sus caracteres específicos; somos hombres, pero al mismo tiempo, podemos vivir y morir con nombre propio; más allá de nuestra vida biológica, poseemos una vida biográfica. ${ }^{17}$

El Poema de Parménides se encarna en la vida de un hombre concreto de carne y hueso; su contenido universal se corporiza en una vida personal, a la cual comunica un nuevo modo de ser, amplificando los horizontes que le vienen impuestos por el género y la especie del individuo humano. La vida que insufla su actualidad al Poema, devolviéndole su naturaleza originaria, que es la de una actividad espiritual — no olvidemos que su fijación sobre el papel es sólo la cáscara, la envoltura, de una visualización interior-, es una vida concreta, personal, individual; al mismo tiempo, empero, el contenido representativo de la obra parmenídea rebasa los límites de toda existencia singular, abriéndose en sus pretensiones hasta abrazar la totalidad de lo que es.

Esta tensión entre lo universal y lo singular la resuelve magistralmente Cayetano distinguiendo, en el seno de lo universal, dos aspectos: «el universal es algo que debe considerarse en dos sentidos [duplex], a saber, en el ser [in essendo] y en la representación [in rapraesentando]» ${ }^{18}$. La esencia inteligible abstraída por el entendimiento agente de la materia individual con la cual se encuentra indisolublemente unida en los singulares sensibles - en el caso que nos ocupa, el Poema de Parménides, una vez ha sido abstraído de las palabras sensibles a través de las cuales nos ha sido transmitido y en las cuales se encontraba

${ }^{17}$ «El Creador divino no puede producir en serie porque se lo prohíbe el carácter soberanamente intuitivo de su inteligencia, por cuyo motivo está influyendo de continuo creadoramente hasta en la última diferencia individual de cada una de sus creaturas. Es que, al fin de cuentas, se trata de una Intuición creadora. En cambio, la producción en serie sólo puede brotar de una inteligencia que, como la nuestra, se halle sujeta a los procedimientos abstractivos, y que deje escapar, por ende, los rasgos propiamente individuales de los entes [que vayan tomando cuerpo al calor de sus efluvios artesanos]. De aquí deduciremos que cada uno de los entes de la Naturaleza se le presenta a Dios - y se nos presenta también, en cierto modo, a nosotros - como un caso absolutamente único. Por ello decíamos hace un momento que Dios llama a cada creatura con nombre propio, y este nombre, además de ser intransferible, penetra hasta las profundidades insondables de la Nada. Por ello también es por lo que cada individuo humano — según lo decíamos hace poco- puede convertirse, llegada la ocasión, en una personalidad excepcional, hasta el punto de que se verá obligado a serlo para poder cumplir con eficacia las funciones que le han cabido en suerte como creatura de Dios [LIRA, Osvaldo, El misterio de la poesía. I. El poeta, Santiago de Chile, Ediciones Nueva Universidad, 1974, pp. 26-7]».

${ }^{18}$ CAYETANO: In De ente et essentia D. Thomae Aquinatis Commentaria, ed. M.-H. Laurent, Torino, Marietti, 1934, cap. IV, q. 8, n.78, p. 117. 
meramente como inteligible en potencia - no es universal «in essendo», sino «in repraesentando», esto es, en su relación con el objeto externo al alma del cual es una semejanza. El ejemplo propuesto por el Doctor Angélico es muy clarificador: «si se diese una estatua corpórea que representase a muchos hombres, resultaría evidente que aquella imagen o especie de la estatua tendría un ser [esse] singular y propio en la medida que existiría en esta materia, pero que tendría la razón de comunidad en la medida que fuera comúnmente representativa de muchos»» ${ }^{19}$.

El contenido universal del Poema, sin embargo, siempre tendrá, inevitablemente, resonancias personales. Esta afirmación puede justificarse con profundas razones metafísicas: la actualidad inteligible del espíritu humano, que es la «luz del entendimiento agente», tiene su raíz en el «ser mismo de una forma no compuesta con la materia» ${ }^{20}$, a saber, en el acto primero de la hipóstasis humana, que es lo que hay de «más íntimo» y de «más profundo» en ella; ${ }^{21}$ lo que ilumina las imágenes sensibles y abstrae de ellas las especies inteligibles que perfeccionarán al entendimiento posible, constituyendo una unidad entre lo inteligible y el inteligente, hunde sus raíces en el «esse» mismo de la persona humana, el cual, según Aristóteles y Santo Tomás, es su propia vida: «el vivir es para los vivientes su "esse"».. ${ }^{22}$

Bajo la luz de lo más íntimo y profundo de su persona, que es «una cierta semejanza participada de la Luz increada» ${ }^{23}$, el filósofo contemplará al Poema de Parménides, o, más exactamente, será una sola vida con él; cuanto mayor sea el grado de penetración en su contenido universal, es decir, cuanto más intensa sea la iluminación ejercida por el entendimiento agente sobre las imágenes de la fantasía, tanto mayor será la intimidad con que

\footnotetext{
${ }^{19}$ SANTO TOMÁS, De ente et essentia, c. 3.

${ }^{20}$ CANALS, Francisco, «Ser i pensar», en: ÍDEM, Tomás de Aquino. Un pensamiento siempre actual y renovador, op. cit., p. 157.

${ }^{21}$ «Esse autem est illud quod est magis intimum cuilibet, et quod profundius omnibus inest, cum sit formale respectu omnium quae in re sunt [SANTO TOMÁs, Summa Theologiae, I, q.8, a.1, in c]».

${ }^{22}$ SAnto TomÁs, Summa Theologiae, I, a.18, a. 2, sed contra. Por el ser como acto podemos explicar la vida como un grado de perfección que ocupa una posición determinada en la escala de los seres: «El mismo "esse" se compara a la vida, y a las otras perfecciones de este tipo como lo participado al participante, porque también la misma vida es un cierto ente; así pues, el "esse" es anterior y más simple que la vida y que las otras perfecciones y se compara a ellas como su acto [SANTO TOMÁS, In De divinis nominibus, cap. 5, lect. 1]».

${ }^{23}$ SANTO TomÁs, Summa Theologiae, I, q. 84, a.5, in c.
} 
el Poema se entrelazará con la vida personal del sujeto cognoscente. La contraposición entre subjetividad y universalidad se revela aquí como un malentendido filosófico. ${ }^{24}$

El profesor honesto no explicará el Poema de Parménides si antes no le ha insuflado, de algún modo, su mismo «esse» personal, ${ }^{25}$ si previamente no lo ha procesado y asimilado haciéndolo su propia vida, pues como establece el adagio escolástico, con una enorme fuerza metafísica y pedagógica, «prius vita quam doctrina», «primero es la vida que la enseñanza» ${ }^{26}$.

\section{Todo pensar es un acto «creativo» y «original». La «palabra del corazón» en la escala de la vida}

Pero es que el profesor de filosofía del que estamos hablando no se limita a «ser» el Poema por medio de las semejanzas representativas que ha abstraído el entendimiento agente, sino que, además, lo «crea» de nuevo, lo «forma» interiormente, lo «pronuncia» en una palabra

\footnotetext{
${ }^{24}$ Las resonancias personales que inevitablemente acompañan a toda intelección tienen su causa principal en el modo «interior» de individuación de la especie universal por la luz del entendimiento agente, que es su acto y, a través de ella, el del entendimiento posible. Sin embargo, también podemos explicar tales reverberaciones individuales, en menor medida, a partir de otro proceso, que, si bien es un momento constitutivo de la intelección de lo universal, connota un inevitable componente de «exterioridad»: la llamada «conversio ad phantasmata». Esta conversión a la imagen es «como una reflexión [SANTO TOMÁs, Summa Theologiae, I, q.81, a.1, in c]» por la cual el sujeto, al mismo tiempo que entiende lo universal, deviene consciente de su originación en las imágenes de la «phantasia». Mediante esta consciencia, el hombre puede referir lo que entiende — la esencia universal— a lo singular percibido y representado en las imágenes, sobre las cuales se había aplicado la acción iluminadora del entendimiento agente, para abstraer de ellas las «especies impresas», que son el principio especificativo de la intelección [Ibídem, I, q.84, a.7, in c]. Como las imágenes sensibles a las cuales referimos lo universal son privativas de cada uno, y dependientes de su intransferible experiencia vital, girándose o convirtiéndose hacia ellas, lo universal «se encarna» en la experiencia de un individuo concreto, sin perder, por ello, la amplitud de su valor representativo. Así como el primer procedimiento «individúa» las especies universales «interiormente», corporeizándolas en una luminosidad arraigada en la actualidad inteligible que pertenece al «esse» de la persona humana por su subsistencia al margen de la materia; el segundo procedimiento «individúa» el universal «exteriormente», refiriéndolo al conocimiento de lo singular sensible adquirido por medio de los sentidos [Cf., BofiLl, Jaume, «D’una teoria de l'acte a una teoria de la relació interpersonal. Notes d'ontologia», op. cit., p. 27 / CANALS, Francisco, «Verdad transcendental y subsistència espiritual en Santo Tomás», en: Convivium, núm. 46, 1975, pp. 109-129].

${ }^{25}$ No se pueden desvincular el «esse» y el «obrar» por razón de la accidentalidad del segundo en el ente finito; sería un error reducir el acto del entendimiento informado por las «species» intencionales a un mero acto adjetivo, pues así no podríamos razón de la apertura a devenir todas las cosas que le conviene en virtud de su naturaleza cognoscente. El mismo Cayetano decía sobre la intelección: «intellectus procedens de potentia ad actum non nisi ad perfectionem sui esse procedit [Cf., CAYETANO, In De Anima, III, c.5]».

${ }^{26}$ Petrus de SCALA, Super Mt., cap. 5, lect. 4.
}

Volumen 2. Número 1. Enero - Junio 2022

ISSN: 2745-0333 (En línea) 
que es «luz» de su «luz», «acto» intelectual de su «acto» intelectual, «vida» de su «vida». Pensar es siempre un acto «creativo» y «original», incluso cuando se piensa lo ya pensado por otro, esto es, lo que no constituye ninguna «novedad». ${ }^{27}$

Gustav Mahler, en una carta fechada el 27 de junio de 1909, escribe a su esposa Alma: «El hombre, y probablemente todas las formas de vida, es incesantemente productivo» ${ }^{28}$. Con esta genial intuición, el compositor, muy probablemente sin saberlo, suscribe una importante tesis metafísica de Tomás de Aquino, la que establece la comunicatividad, difusividad o fecundidad, que pertenece al acto en cuanto acto: «Es de la naturaleza de cualquier acto que se comunique a sí mismo en cuanto es posible. Por lo cual, toda agente obra según que es en acto [unumquodque agens agit secundum quod in actu est]. Y obrar no es otra cosa que comunicar aquello por lo cual el agente es en acto, en la medida de lo posible» ${ }^{29}$.

Santo Tomás, una vez presupuesto este principio, distingue entre dos géneros de operatividad: «Hay una doble operación [duplex operatio]. Una es transeúnte, desde el operante a algo extrínseco, como el calentamiento de la madera por parte del fuego, y esta operación no constituye una perfección para el operante, sino para lo operado, pues el fuego, ciertamente, no adquiere nada por el hecho de calentar, sino que, por la acción de calentar, algo adquiere

\footnotetext{
${ }^{27}$ Seguir un gran Maestro no sólo no ahoga la tendencia de nuestro entendimiento a la «creatividad», sino que la fecunda; y al revés, la presión constante para decir y escribir «novedades», puede bloquearla, atarla, reducirla a la esterilidad y a la trivialidad. El obispo tomista catalán Josep Torras i Bages, haciendo referencia a este mismo asunto, escribió una carta para que se leyera y se comentara en el Seminario de su diócesis, a raíz del «motu proprio» Doctoris Angelici, que el Papa San Pío X había dedicado a la enseñanza de Santo Tomás. El Papa, en este texto, advertía «a quienes se dedican a enseñar filosofía y teología, que el separarse de las huellas de Santo Tomás, principalmente en cuestiones de metafísica, no será sin gran detrimento [Pío X, Doctoris Angelici 29VI-1914, AAS 6 (1914), p. 336]». Torras i Bages, en esta carta fechada el 20 de octubre de 1914, escribe: «El sistema de que cada profesor pretenda gozar del privilegio de originalidad es contrario a la realidad de las cosas. Son pocos los que han nacido para maestros, y la mayor parte de los hombres debemos contentarnos con ser discípulos. Hasta el mismo procedimiento en la exposición de la doctrina, como las fórmulas que contienen las ideas, forman parte del mérito del maestro, y así es que su intérprete no ha de querer ser original, sino únicamente poner en evidencia los conceptos del hombre excepcional, que las generaciones han considerado como una inteligencia superior a la generalidad de sus semajantes [TORRAS I BAGES, Josep, «Carta sobre el "motu proprio" de Pío X "Doctoris angelici nemo"» en: ÍDEM, Obres completes, vol. X, Barcelona, Publicacions de l'Abadia de Montserrat, 1994, p.96 / Forment, Eudaldo, «En el centenario de "La tradició catalana" de Torras i Bages», en: Espíritu, núm. 106, 1992, pp. 139-152]».

${ }^{28}$ MAHLER, Alma, Gustav Mahler. Recuerdos y cartas, (trad. Néstor Míguez), Madrid, Taurus, 1978, carta del lunes 27 de junio de 1909, p. 333.

${ }^{29}$ Santo Tomás, De Potentia, q.2, a.1, in c.
} 
el calor. Otra es la operación que no pasa a algo extrínseco, sino que permanece en el mismo operante [manens in ipso operante], como entender, sentir, querer y otras de este tipo. Esas operaciones son perfecciones del operante mismo, pues el entendimiento no es perfecto sino en cuanto es inteligente en acto. El primer género de operaciones es común a los vivientes y a los no vivientes. Pero el segundo género de operaciones es propio de los vivientes. Si tomamos el término "movimiento" en sentido amplio para designar cualquier tipo de operación, como hace el Filósofo en el libro III De anima, donde se afirma que "sentir y entender son un cierto movimiento", y no lo entendemos en el sentido de "acto de lo imperfecto", como se define en el libro III de la Physica, sino como acto de lo que es perfecto [actus perfecti], entonces también parece ser algo propio de los vivientes» ${ }^{30}$.

Las operaciones transeúntes y las operaciones vitales, las que causan un efecto extrínseco al agente y las que perfeccionan al mismo agente, tienen un origen común: la actualidad del operante que, como toda actualidad en los entes, se constituye desde el acto de «esse». El carácter dinámico, comunicativo, operativo, difusivo, del acto no se manifiesta únicamente en los entes naturales, sino también en los vivientes, por lo cual también a ellos se les puede atribuir el movimiento, aunque, en este caso, no debe considerarse como «acto de lo imperfecto», a saber, de lo que está en potencia en cuanto está en potencia, sino «de lo perfecto», a saber, del operante en cuanto está en acto.

Los dos géneros de operaciones, además de tener en común el origen, comparten un mismo término, que consiste en la emisión o generación de algo: «Según uno y otro género de operaciones, hallamos en las criaturas alguna procesión [aliqua processio]. Pues decimos que lo engendrado procede del generante [el grillo del grillo], y que lo hecho procede del que lo hace [el zapato del zapatero]. Pero, en cuanto al segundo género de operaciones, decimos que la palabra procede del que la dice [verbum procedit a dicente], y el amor del amante [amor ab amante]» ${ }^{31}$.

\footnotetext{
${ }^{30}$ SANTO TOMÁs, De Potentia, q.10, a.1, in c.

${ }^{31}$ SAnto Tomás, De Potentia, q.10, a.1, in c.
} 
Toda naturaleza, por su actualidad, se ordena a formar algo, el término (extrínseco o inmanente) de su actividad. Este principio universal, fundado en la naturaleza comunicativa que compete a cualquier ente por su orden al «esse», es anunciado explícita e inequívocamente por Santo Tomás: «según la diversidad de las naturalezas, se halla en las cosas diversos modos de emanación; y cuanto más alta es una naturaleza, tanto más íntimo es lo que emana de ella [tanto id quod ex ea emanat, magis ei est intimum]» ${ }^{32}$.

Santo Tomás dibuja una impresionante escala desde los cuerpos inanimados hasta la misma divinidad, subiendo a partir de los diversos grados de intimidad entre el término emanado y el principio emanante; esos grados son correlativos a los diversos niveles de «esse» que constituyen los distintos eslabones de la escala de los seres.

En el peldaño más bajo, el de menor entidad y mayor exterioridad en la operación emanativa, encontramos a los cuerpos inanimados, «cuyas emanaciones sólo pueden causarse por las acciones de los unos sobre los otros $)^{33}$; un cuerpo que está quemando en acto, por ejemplo, puede hacer que otro, por su contacto, se convierta a la cualidad y especie del fuego.

El segundo peldaño de la escala de los seres - el de los vegetales - constituye el primer grado de la vida; la principal diferencia entre los vivientes y los cuerpos inanimados es que los primeros «se mueven a sí mismos a obrar, mientras que aquellos que no se mueven sino por impulsos exteriores, carecen completamente de vida». La emanación de las plantas, que es la formación del fruto, ya tiene un origen interior: «en las plantas, la emanación ya procede de dentro [ex interiori procedit], puesto que el humor interno de la planta se convierte en semilla, y ésta, enviada a la tierra, crece y se convierte en planta». La vida de las plantas, sin embargo, es imperfecta: «aunque la emanación proceda en ellas del interior, sin embargo, lo que emana, saliendo progresivamente desde dentro, acaba por convertirse en algo totalmente extrínseco. Pues el humor del árbol, saliendo primeramente de él, se convierte en flor y después en fruto, separado de la corteza del árbol, pero sujeto a él; y llegando a su madurez, se separa totalmente

${ }^{32}$ SANTO TOMÁs, Summa contra Gentiles, IV, cap. 11.

${ }^{33}$ Ídem. Hasta que no indiquemos lo contrario, los textos citados pertenecerán a este fragmento. 
del árbol y, cayendo en tierra, produce por su virtud seminal otra planta». De hecho, si se considera esta emanación detenidamente, resultará manifiesto que su principio, hablando con propiedad, también es exterior: «pues el humor intrínseco del árbol se toma por las raíces de la tierra, de la cual recibe la planta su nutrición».

El siguiente grado de la vida es el que pertenece a los entes con alma sensitiva, «cuya emanación propia, aunque comience en el exterior, termina en el interior, y, cuanto más progresa la emanación, tanto más penetra en la intimidad [quanto emanatio magis processerit, tanto magis ad-intima devenitur]. Por ejemplo, lo sensible imprime exteriormente su forma en los sentidos externos, pasa de ellos a la imaginación y después al tesoro de la memoria». No obstante, en esta emanación siempre se da una cierta exterioridad, porque, en cualquiera de sus procesos (el del sentido externo, el de la imaginación o el de la memoria sensible, que son las operaciones mencionadas en el ejemplo anterior), el principio y el término son cosas diversas: «ninguna potencia sensitiva vuelve sobre sí misma [non enim aliqua potentia sensitiva in seipsam reflectitur]», o, dicho de otro modo, lo sensible nunca se identifica con el sentiente.

El grado de vida supremo y perfecto es el propio del entendimiento, porque «el entendimiento se vuelve sobre sí mismo, y se puede entender a sí mismo [intellectus in seipsum reflectitur, et seipsum intelligere potest]». La actualidad intelectual desemboca en el «parto» de una palabra interior, inteligible, espiritual, en la cual se expresa y se manifiesta lo que el entendimiento está entendiendo en acto; al mismo tiempo que el inteligente entiende, se forma en su interior lo concebido, que es lo entendido por antonomasia, la «intentio intellecta».

La fecundidad generativa de la cual emana la palabra interior o «verbum cordis» no debe considerarse como un «movimiento» por el cual el ente en potencia pasa al acto, sino que nace del entendimiento en cuanto éste existe en acto y, simultáneamente con su existir en acto, engendra en él el verbo concebido. Porque, en efecto, las operaciones vitales o inmanentes que constituyen los actos de conocimiento no son como las acciones causativas de un efecto fuera del agente — las acciones predicamentales o transeúntes_-, que implican siempre con 
un movimiento sucesivo. Las operaciones de la vida, según indica Francisco Canals, «tienen un modo de fecundidad en que, simultáneamente con su ser en acto, que es ser locutivo y manifestativo, queda puesto en la intimidad del cognoscente la imagen o palabra expresada» ${ }^{34}$. La imagen o «phantasma» es el término inmanente de la operación de la «phantasia» o imaginación; el «verbum cordis» es «eructado» ${ }^{35}$ por el entendimiento en acto, mediante un «proceso perfecto del acto al acto [processus perfectus de actu in actum], en el cual no se requiere ninguna especie de movimiento ${ }^{36}$. La manifestatividad o locutividad pertenece a la misma naturaleza del acto de entender: «el verbo no se origina a partir de nuestro entendimiento, sino en la medida que éste existe en acto, pues el existir en acto y el ser concebido el verbo en él es simultáneo [...]. La generación del mismo verbo no es según una salida de la potencia al acto [exitum de potentia in actum], sino que se origina como un acto del acto [oritur actus ex actu], como el esplendor de la luz [splendor ex luce], como la razón entendida del entendimiento en acto [ratio intellecta ex intellectu in actu]» ${ }^{37}$.

La comparación entre la concepción y el parto corporales y la concepción y el parto inteligibles resulta de gran utilidad para comprender la naturaleza del término inmanente de la actividad intelectiva: «la prole, mientras es concebida y está encerrada [clauditur] en el

\footnotetext{
${ }^{34}$ Canals, Francisco, «¿Casi desconocida la síntesis filosòfica de Santo Tomás?, en: ÍDEM, Tomás de Aquino. Un pensamiento siempre actual y renovador, op. cit., p. 51.

${ }^{35}$ Esta metáfora profundamente filosófica y artística, aunque repugnante a los refinamientos del lenguaje de la civilización, remite al Psalmo 44 de la Vulgata, que empieza diciendo: «Eructavit cor meum verbum bonum», «Mi corazón ha eructado un verbo sublime». Santo Tomás, en su comentario al Psalmo citado, comenta este versículo de la siguiente manera: «La publicación [editio] de este Psalmo es descrita a partir de las siguientes palabras: "mi corazón eructa un verbo bueno". La eructación procede de una excesiva plenitud, de una repleción; de este modo se significa que se habla desde una abundancia de devoción y de sabiduría [ex abundantia devotionis et sapientiae]. "La boca habla desde la abundancia del corazón (Mt 12,34) [ex abundantia cordis os loquitur]". Debe notarse que la publicación de este Psalmo se atribuye al corazón que lo ha compuesto desde una grande devoción, pues David no es de estos de quienes se dice: "este pueblo me honora con los labios, mas su corazón está lejos de mi [Mt 15, 8]"; más bien es de los que proclama con el corazón las alabanzas [laudes] de Cristo: "cantaré con el espíritu y cantaré con la mente (I Co 14, 15)". Este corazón ha eructado una palabra, y esta palabra es este Psalmo».

Nos interesa destacar aquí que el verbum cordis, que designa el verbo del hombre en toda su plenitud, en toda su perfección, es un «eructo» por el hecho que procede de una «plenitud excesiva [ex nimia plenitudine]», que se desborda formando la palabra interior. Queda perfectamente claro que el verbo mental no se forma por la indigencia del entendimiento sino por su actualidad cognoscitiva, cuya plenitud y abundancia no se pueden contener [SANTO TOMÁs, Super Psalmo 44, n.1].

${ }^{36}$ Thomas de SutTon (?), De natura verbi intellectus, cap. 1.

${ }^{37}$ SAnto Tomás, Summa contra Gentiles, IV, cap. 14.
} 
útero, todavía no tiene la última perfección, para que subsista por sí misma como distinta del generante en cuanto al lugar; por eso, en la generación corporal de los animales hay que distinguir entre la concepción de la prole engendrada, y el parto, mediante el cual la prole engendrada se separa del generante según el lugar, saliendo del útero del generante [...]. Pero, como la concepción y el parto en las cosas corporales son con movimiento, ${ }^{38}$ es necesario que entre ellos se dé una cierta sucesión, ya que el término de la concepción es la existencia de lo concebido en el concipiente [esse concepto in. concipiente], mientras que el término del parto es que el existir de lo que es parido [esse eius qui paritur] se distinga del que lo está pariendo [a pariente]. En consecuencia, es necesario que, en las cosas corpóreas, lo que es concebido [id quod concipitur] todavía no sea, y que aquello que es parido [id quod parturitur], en la acción de parir [in parturiendo], no sea algo distinto del que lo está pariendo [non sit a parturiente distinctum]. Pero la concepción y el parto inteligible [partus intelligibilis] no es con movimiento, ni con sucesión; por eso, al mismo tiempo que [el concepto] es concebido, existe; y al mismo tiempo que es parido, es distinto; así como lo que se ilumina [quod illuminatur], al mismo tiempo que se ilumina [simul dum illuminatur], queda iluminado [illuminatum est], de tal modo que, en la iluminación, no hay ninguna sucesión. Y todo esto, si ya se encuentra en nuestro verbo inteligible, mucho más competerá al Verbo de Dios, porque no sólo es una concepción y parto inteligible, sino porque ambas cosas existen en la eternidad, en la cual no puede haber ni antes ni después [prius et posterius esse non possunt]» ${ }^{39}$.

Aquí, en la obra propia de la vida intelectual, que es la «concepción» y el «parto» de la «palabra del corazón», también hay que distinguir diversos grados, que dependen de la intensidad con que el cognoscente posea el acto de «esse».

El entendimiento humano es el más bajo entre los seres intelectuales, porque su conocimiento tiene su origen en la sensibilidad, y no puede entender nada sin recurrir a imágenes sensibles,

\footnotetext{
${ }^{38}$ Aquí se entiende el movimiento en el sentido de actualización progresiva de lo que está en potencia. Como la concepción y el parto corporales son operaciones cuyos respectivos términos requieren un proceso, un desarrollo, para poder alcanzarse, también será indispensable que se dé una sucesión entre ambas operaciones, en tanto que, para parir, es indispensable haber concebido antes.

${ }^{39}$ SANTO TOMÁs, Summa contra Gentiles, IV, cap. 14.
} 
ni siquiera a su propia naturaleza. El segundo nivel es el del entendimiento angélico, que, si bien «no procede a partir de algo exterior para conocerse a sí mismo, sino que se conoce a sí mismo por sí mismo [per se cognoscit seipsum]» ${ }^{40}$, no constituye la última perfección de la vida, porque, en los ángeles, la «intentio intellecta» — es decir, el objeto concebido, la palabra mental, la «species expressa» que procede del acto intelectual por el cual el ángel se conoce a sí mismo - no puede identificarse con su substancia. Cuando un ángel se entiende no procede de este conocimiento otro ángel; esto se explica porque «en los angeles no son lo mismo el entender y el "esse"» ${ }^{41}$. La última perfección de la vida compete a Dios «en el cual no se distingue el entender del "esse" [...], de ahí que en Dios la "intentio intellecta" se identifique necesariamente con la misma esencia divina» ${ }^{42}$.

En todas las formas de vida $-\mathrm{y}$, en cierto sentido, incluso podríamos decir en todos los entes - se revela una tendencia a la «productividad», a la «creatividad» ${ }^{43}$, a la «operatividad», a manifestar la plenitud rebosante en cada una de ellas mediante una «obra vital», que brota del operante en acto como «vida» de la «vida», como «acto» del «acto», como «esplendor» de la «luz»; así se engendra el fruto en las plantas, la imagen en los animales y la palabra del corazón en los seres intelectuales.

\footnotetext{
${ }^{40}$ SAnto TomÁs, Summa contra Gentiles, IV, cap. 14. Para Santo Tomás no pueden existir «inteligibles subsistentes», esencias realmente separadas de la materia, sin estar siempre en acto de entenderse a sí mismas: «el ángel, por ser inmaterial, es una cierta forma subsistente y, por ello, es inteligible en acto. Se sigue, por lo tanto, que se entiende a sí mimo [seipsum intelligat] por su forma, que es su substancia [SANTO TOMÁs, Summa Theologiae, I, q. 56, a.1, in c]». Sin embargo, no por ello podemos identificar, sin más, el «intelligere» del ángel con su «esse», pues si bien por la actualidad inteligible de su forma puede conocerse a sí mismo, no puede conocer las otras cosas, esto es, la universalidad del ente y de lo verdadero [Cf., Ibídem, I, q.54, a.2, ad 2]. A diferencia del Verbo divino, consubstancial al Padre que lo dice, a la intelección del ángel y a la palabra que dimana de su actualidad les corresponde una inherencia cualitativa.

${ }^{41}$ SAnto TomÁs, Summa contra Gentiles, IV, cap. 14.

${ }^{42}$ Ídem.

${ }^{43}$ «Es preciso que nos convenzamos de una vez por todas de que la poesía pura sólo puede adquirir vigencia en Dios, por lo cual eso mismo que en nosotros llega a surgir con caracteres de creación o poesía deberá ser mirado como un puro y simple analogado menor de aquel analogado principal que es la poesía divina [LiRA, Osvaldo, El misterio de la poesía. I. El poeta, op. cit., p. 12]».
} 


\section{3. «El genio hace a todo el mundo un poco genio»}

Mahler, en la carta antes aludida, después de afirmar la «productividad» del hombre y, probablemente, de todas las formas de vidas, continúa: «Esto ocurre inevitablemente en todas las etapas, como consecuencia de la vida misma. Cuando la energía de producción decae, la entelequia muere; esto es, debe adquirir un nuevo cuerpo» ${ }^{44}$. La palabra «entelequia», en su significado metafísico originario, hace referencia a lo que es actual en la línea de la substancia corpórea, a la «forma substancial», por la cual el compuesto se mantiene unido y posee la perfección que le corresponde, como la vida, en el caso de los animales; análogamente, cuando la «creatura poética» ${ }^{45}$ pierde su capacidad para expresar la plenitud de vida que, en su momento, la originó, cuando deja de ser «acto» del «acto», pierde para el poeta todo sentido, y su plasmación sobre la materia - ya sea papel, mármol, lienzo, sonido o movimiento coreográfico - deviene para él un mero «cadáver», una «palabra muerta», un simple testimonio de lo que antaño fue una proyección verdadera de su vida personal. Cuando esto ocurre, en la experiencia del artista, «la entelequia muere», el acto que infundía la vida a la materia corpórea se separa de ella, y el creador humano debe buscar entonces manifestar su personalidad por medio de otra «obra vital», por medio de otra «palabra del corazón».

Esta proyección de uno mismo en su excepcionalidad, en su unicidad, en su irreiterabilidad, por medio de una «palabra» que es una íntima obra de la vida, constituye una tendencia inscrita en toda forma de vida personal y, por ende, en toda hipóstasis humana; por ello, emprender esta obra no es un privilegio reservado a unos escogidos, aunque sólo unos pocos, los hombres de genio, lograrán de un modo remarcable la proyección de la propia personalidad en una «creatura poética»: «En la etapa en que se encuentran los hombres de desarrollo superior, la producción (que es natural en la mayoría bajo la forma de la reproducción) va acompañada de un acto de autorrealización; por ello, su creatividad se eleva [...]. Ésta es, pues, la fuente de

\footnotetext{
${ }^{44}$ MAHLER, Alma, Gustav Mahler. Recuerdos y cartas, op. cit., p. 333.

${ }^{45}$ Siguiendo a Osvaldo Lira, llamamos poesía a la «proyección de un momento integral, pero sin embargo esporádico y fugaz, de la propia personalidad sobre los materiales de una obra por estructurar o por realizar [LIRA, Osvaldo, El misterio de la poesía. I. El poeta, op. cit., p. 14]»; esta definición permite incluir dentro de la expresión «creatura poética» a cualquier manifestación de la creatividad humana, aun en el caso de las disciplinas científicas o filosóficas.
} 
la inquietud de tales hombres. En medio de los breves momentos en la vida del hombre de genio en que se responde a esos desafíos, están los largos tramos estériles de la existencia que oprimen el alma con anhelos inalcanzables. Justamente esta lucha incesante y sus tormentos es lo que da su carácter a la vida de esos pocos» ${ }^{46}$.

La actividad productiva del profesor de filosofía de nuestro ejemplo se manifiesta «bajo la forma de la reproducción»; ciertamente, él no es el autor del Poema, pero al mismo tiempo que lo estudia, que se hace una sola vida con él, va generando en su interior una palabra expresiva de lo que está entendiendo, que será tanto más perfecta, tanto más íntima y tanto más «creativa» — esto es, tanto más «causativa» de un término inmanente-, cuanto mayor haya sido su penetración en el contenido inteligible del texto; cuanto más excave o profundice en él, tanto más se manifestará a sí mismo al revelar interiormente el Poema.

No por seguir a un gran maestro del pasado el filósofo encadena o ahoga la dinamicidad intrínseca de su vida personal, que está ordenada a «concebir» y a «parir» interiormente una palabra en la que se proyecte su propia personalidad; más bien, este seguimiento fecunda la intelección y la lleva a un grado de actualidad y plenitud que el individuo humano que no es un genio jamás hubiera podido alcanzar por sí mismo; como dice Josep Torras i Bages: «es indudable que el genio lo que pretende, y aquí está la razón de su superioridad y la de su característica facultad, es hacer participante a todo el mundo, a todo su público, a todos los contempladores de su obra, de su genialidad, hacer a todo el mundo un poco genio» ${ }^{47}$. Esta plenitud en la operación vital de la intelección se desborda en la formación de una «ratio intellecta» que procede de la primera «como un acto del acto, como el esplendor de la luz» ${ }^{48}$; por esta razón, la lectura atenta de un gran maestro implica siempre una originalidad y una espontaneidad activa por parte del lector; ciertamente, esta originalidad y esta espontaneidad están mediadas instrumentalmente por el autor, pero no por ello pierden su carácter de

\footnotetext{
${ }^{46}$ MAHLER, Alma, Gustav Mahler. Recuerdos y cartas, op. cit., p. 333.

47 Torras I BAgES, Josep, «Del verb artístic», en: ÍDEM, Obres completes, vol. 2, Barcelona, Publicacions de l'Abadia de Montserrat, 1994, p. 322.

${ }^{48}$ SANTO TOMÁs, Summa contra Gentiles, IV, cap. 14.
} 
originalidad y espontaneidad, así como el uso del bastón no impide que uno camine por sí mismo.

\section{La técnica pedagógica se ordena a la vida}

La preparación de una clase sobre Parménides no puede explicarse en términos exclusivamente profesionales o técnicos, como una mera actividad transeúnte o predicamental, pues, estudiando a Parménides, el profesor de filosofía tiende a la plena actualización de sus posibilidades connaturales, busca colmar una necesidad vital de «productividad», de «creatividad», de «emanatividad». Sobre esta necesidad se expresa Mahler en un fragmento que coincide con la interpretación tomista de la palabra del corazón —ya sea una obra artística o doctrinal — como una emanación vital: «Este es el sentido, mi querida Almschi, de todo lo que te ha ocurrido, de todo lo que se ha depositado en ti, como una necesidad del crecimiento del alma y la forja de la personalidad. Y tú aún tienes una larga vida por delante. Persiste en el ejercicio de esta fuerza interior (como haces, en verdad); aspira al máximo de belleza y poder (más que esto ninguno puede hacer, y ello, sólo los elegidos, en todo caso); "expande tu yo"; ejercítate en la belleza, en la bondad; crece incesantemente (ésta es la verdadera productividad), y ten la certeza de lo que siempre sostengo: lo que dejamos detrás es sólo la cáscara, la envoltura. Los Meistersinger, la Novena, Fausto sólo son la cáscara desechada. Como lo son, hablando con propiedad, nuestros cuerpos. Por supuesto, no quiero decir que la creación artística sea superflua. Es una necesidad del hombre de crecimiento y alegría, lo cual es también una cuestión de salud y energía creadora. Pero ¿qué necesidad real hay de las notas?» ${ }^{49}$.

La clase de filosofía, igual que una obra de arte, no puede agotarse en su dimensión externa, en la que aparece como una actividad predicamental, transeúnte. Ésta es sólo su «cáscara», su «envoltura». La clase de filosofía es, por encima de todo, la corporeización, la exteriorización, de una íntima necesidad de la vida intelectiva, la de manifestarse internamente a sí misma en

\footnotetext{
${ }^{49}$ MAHLER, Alma, Gustav Mahler. Recuerdos y cartas, op. cit., p. 333.
} 
una palabra que emana sin movimiento alguno de la intelección actual como «actus actus actum possidentis [acto del acto que posee el acto]» ${ }^{50}$. La vida de una hipóstasis humana, al manifestarse a sí misma, no sólo se manifiesta a sí misma, pues está ordenada por naturaleza — debido a la no inmersión de su forma substancial en la materia- a ser intencionalmente todas las cosas. ${ }^{51}$ En la locutividad propia del entendimiento en acto, el sujeto intelectivo realiza su tendencia natural a «transcender» sus límites entitativos, a ensanchar su vida personal, a — digámoslo con Mahler- «acrecentar su alma», a «expandir su yo», a «forjar una personalidad», a «ejercitarse en la belleza y en la bondad», a «crecer incesantemente». La proyección de uno mismo en una íntima obra de la vida no patentiza un narcisismo gnoseológico, sino que implica más bien lo contrario: una infinita apertura a la verdad del ente, porque el viviente personal jamás podrá decirse plenamente, sin decir, al mismo tiempo, el orden entero del universo y de sus causas. ${ }^{52}$ La manifestación de uno mismo en su excepcionalidad, incluye una apertura a la universalidad de lo que es. La palabra humana se revela, de este modo, como una imagen analógica del Verbo divino, en el cual están precontenidas todas las cosas: «omnia per ipsum facta sunt, et sine ipso factum est nihil, quod factum est» ${ }^{53}$.

Así como la intelección en acto se desborda en el «verbum cordis», éste tiende a manifestarse en la imagen ejemplar de la palabra sensible que va a pronunciarse y, por medio de ésta, en el «verbum vocis». El siguiente texto, donde Santo Tomás compara la generación de la palabra con la producción de una obra artística, resulta muy clarificador: "Así como en el artesano consideramos tres cosas, es decir, el fin perseguido por él, el ejemplar y la obra producida; igualmente, en el que habla encontramos tres verbos, esto es, aquel [verbo] que es concebido por el intelecto, y para la significación del cual se profiere el verbo exterior: y esto es el verbo del corazón [verbum cordis] pronunciado sin voz; el ejemplar del verbo exterior: y eso se dice del verbo interior - interior porque no se encuentra fuera del alma, en el mundo físico - que consiste en una imagen de la voz [imaginem vocis]; y el verbo exterior expresado: que se dice

\footnotetext{
${ }^{50}$ Millán Puelles, Antonio, La estructura de la subjetividad, Madrid, Rialp, 1967, pp. 187 y 197-198.

${ }^{51}$ Cf., SANTO TOMÁs, De Veritate, q.2, a.2, in c.

52 Ídem.

${ }^{53}$ Io $1,3$.
} 
verbo de la voz [verbum vocis]. Y así como en el artesano precede la intención del fin, después sigue la invención de la forma artificial, y, por último, produce lo artificial en el ser; igualmente el verbo del corazón es anterior, en quien habla, que la imagen de la voz, y en última posición encontramos el verbo de la voz» ${ }^{54}$.

Esta exteriorización, por la cual aquella íntima operación que constituye la vida del que filosofa se corporeiza en forma de «diálogo», es, precisamente, la clase de filosofía. En el presente estudio, hemos tratado de presentarla en la línea de la perfección del viviente personal, como una obra de la vida que, ciertamente, tiene una parte de actividad transeúnte, sensible, exterior, pero que, sin embargo, no puede reducirse a ella, sin que ello comporte un vaciamiento de su densidad antropológica y, al mismo tiempo, un impedimento para conseguir su finalidad última: que el alumno pueda «concebir» y «parir» en su interior el «verbum cordis» del cual la palabra externa del profesor es signo; que el Poema de Parménides explicado por el profesor - que lo visualiza al mismo tiempo que lo engendra - devenga en el que lo escucha lo mismo que es en la mente del docente y lo mismo que era en la mente de Parménides: no una unidad didáctica, no una materia evaluable, sino una íntima actividad de la vida. La técnica o arte pedagógica debería tener en cuenta el orden intrínseco por el cual la vida humana, mediante la formación de una palabra del corazón, procede a su propia perfección, ${ }^{55}$ y no debería olvidar que el perfeccionamiento vital del profesor es causa (instrumental) del perfeccionamiento vital del alumno; es decir, quien no «produce», quien no «engendra», quien no «crea» interiormente lo que está explicando —independientemente de si se trata o no de una novedad - difícilmente ofrecerá unos medios adecuados para que el alumno conciba y dé a luz, en la intimidad de su mente, a un «verbum cordis». Esta subordinación de la labor docente al dinamismo propio de la vida intelectual viene perfectamente expresada en el adagio escolástico al que más arriba hicimos mención, y que resume la idea central de nuestra investigación: «prius vita quam doctrina», «primero es la vida que la enseñanza» ${ }^{56}$.

\footnotetext{
${ }^{54}$ ÍD., De Veritate, q.4, a.1, in c.

${ }^{55}$ Ver la nota 24.

${ }^{56}$ Petrus de SCALA, Super Mt., cap. 5, lect. 4.
} 


\section{Referencias}

Bofill, J. (1964). «D’una teoria de l'acte a una teoria de la relació interpersonal. Notes d'ontologia», en: Convivium, núms. 17-18.

Canals, F. (1975). «Verdad transcendental y subsistència espiritual en Santo Tomás», en: Convivium, núm. 46, pp. 109-129.

Canals, F. (2004). «Ser y operación», en ÍDEM, Tomás de Aquino. Un pensamiento siempre actual y renovador. Barcelona: Scire, pp. 159-163.

Canals, F. (2004). «Ser i pensar», en: ÍDEM, Tomás de Aquino. Un pensamiento siempre actual y renovador, op. cit., pp. 149-158.

Canals, F. (2004). «¿Casi desconocida la síntesis filosòfica de Santo Tomás?, en: ÍDEM, Tomás de Aquino. Un pensamiento siempre actual y renovador, op. cit., pp. 43-52.

Forment, E. (1992). «En el centenario de "La tradició catalana" de Torras i Bages», en: Espíritu, núm. 106, pp. 139-152.

Forment, E. (2015). Catecismo de la Suma contra los Gentiles. Alicante: Cobel.

Lira, O. (1974). El misterio de la poesía. I. El poeta. Santiago de Chile: Ediciones Nueva Universidad.

Mahler, A. (1978). Gustav Mahler. Recuerdos y cartas, (trad. Néstor Míguez). Madrid: Taurus.

Millán Puelles, A. (1967). La estructura de la subjetividad, Madrid: Rialp. 
Petrus de Scala (2000). Super Matthaeum, en: S. Thomae de Aquino Opera Omnia (Ed. Enrique Alarcón). «Opera aliqua false adscripta Thomae». Pamplona: Corpus Thomisticum: www.corpusthomisticum.org.

Pius X (1914). Doctoris Angelici 29-VI-1914, AAS 6.

Thomas de Sutton (?) (2000). De natura verbi intellectus, en: S. Thomae de Aquino Opera Omnia (Ed. Enrique Alarcón). «Opera aliqua false adscripta Thomae». Pamplona: Corpus Thomisticum: www.corpusthomisticum.org.

Tomás de Aquino (1882 y ss). Sancti Thomae Aquinatis, Doctoris Angelicis, Opera omnia iussu impensaque Leonis XIII, P.M. Edita Roma: Ex Typographia Polyglotta.

Tomás de Aquino (2000 y ss). S. Thomae de Aquino Opera Omnia (Ed. Enrique Alarcón). Pamplona: Corpus Thomisticum: www.corpusthomisticum.org.

Tomás de Vío (Cayetano) (1934). In De ente et essentia comentaria (ed. M.-H. Laurent). Turín: Marietti.

Torras i Bages, J. (1994). «Del verb artístic», en: ÍDEM, Obres completes, vol. 2. Barcelona: Publicacions de l'Abadia de Montserrat.

Torras i Bages, J. (1994). «Carta sobre el “motu proprio” de Pío X “Doctoris angelici nemo”» en: ÍDEM, Obres completes, vol. X. Barcelona: Publicacions de l'Abadia de Montserrat. 
REVISTA INTERNACIONAL DE FILOSOFÍA TEÓRICA Y PRÁCTICA 